OPEN ACCESS

Edited by:

Gene S. Tan,

J. Craig Venter Institute (La Jolla),

United States

Reviewed by:

Felicity Burt,

National Health Laboratory Service

(NHLS),

South Africa

Matthias Niedrig,

Consultant, Berlin, Germany

*Correspondence:

Ciaran Gillbride

ciaran.gilbride@st-annes.ox.ac.uk

${ }^{\dagger}$ These authors have contributed equally to this work

${ }^{\ddagger}$ These authors have contributed equally to this work

Specialty section:

This article was submitted to Vaccines and Molecular Therapeutics, a section of the journal

Frontiers in Immunology

Received: 15 November 2020 Accepted: 01 March 2021 Published: 18 March 2021

Citation:

Gillbride C, Saunders J, Sharpe H, Maze EA, Limon G, Ludi AB, Lambe T and Belij-Rammerstorfer S (2021) The Integration of Human and Veterinary Studies for Better Understanding and

Management of Crimean-Congo Haemorrhagic Fever.

Front. Immunol. 12:629636. doi: 10.3389/fimmu.2021.629636

\section{The Integration of Human and Veterinary Studies for Better Understanding and Management of Crimean-Congo Haemorrhagic Fever}

\author{
Ciaran Gilbride ${ }^{1 * t}$, Jack Saunders ${ }^{1 \dagger}$, Hannah Sharpe ${ }^{1}$, Emmanuel Atangana Maze ${ }^{2}$, \\ Georgina Limon ${ }^{2}$, Anna Barbara Ludi ${ }^{2}$, Teresa Lambe ${ }^{1 \neq}$ and Sandra Belij-Rammerstorfer ${ }^{1 \neq}$ \\ 1 The Jenner Institute, Nuffield Department of Medicine, University of Oxford, Oxford, United Kingdom, 2 The Pirbright \\ Institute, Woking, United Kingdom
}

Outbreaks that occur as a result of zoonotic spillover from an animal reservoir continue to highlight the importance of studying the disease interface between species. One Health approaches recognise the interdependence of human and animal health and the environmental interplay. Improving the understanding and prevention of zoonotic diseases may be achieved through greater consideration of these relationships, potentially leading to better health outcomes across species. In this review, special emphasis is given on the emerging and outbreak pathogen Crimean-Congo Haemorrhagic Fever virus (CCHFV) that can cause severe disease in humans. We discuss the efforts undertaken to better understand CCHF and the importance of integrating veterinary and human research for this pathogen. Furthermore, we consider the use of closely related nairoviruses to model human disease caused by CCHFV. We discuss intervention approaches with potential application for managing CCHFV spread, and how this concept may benefit both animal and human health.

Keywords: CCHF, NSDV, One Health, Hazara, vaccines, veterinary vaccines, mouse model, NHP model

\section{INTRODUCTION}

Zoonotic diseases are caused by pathogens which circulate in vertebrate hosts and periodically spillover into human populations (1). It has been estimated that over $60 \%$ of pathogenic species in humans originally arose from animal populations (2). In the $21^{\text {st }}$ century alone, several zoonotic pathogens have caused epidemics such as SARS (3) and MERS coronaviruses (4), avian influenza (5), and Ebolavirus $(6,7)$, as well as pandemics of swine flu (8) and the newly emerged SARS-CoV-2 (9), which alone has caused an estimated 2.25 million deaths up to February 2021 (10).

While it is difficult to estimate the continuous economic burden of zoonotic disease, localised epidemics and worldwide pandemics can induce instant and deep economic shock which has important secondary impacts on global health outcomes. The 2015 MERS outbreak in South Korea infected 186 confirmed individuals and caused a total of 36 deaths, with the overall economic damage to South Korea approximated at USD $\$ 8.5$ billion $(0.6 \% \mathrm{GDP})(11,12)$. Estimates for the 
larger 2002-2003 SARS epidemic place the economic costs at $\$ 3.7$ billion $(2.6 \%$ GDP) in the Hong Kong epicentre $(13,14)$, while the recent COVID-19 pandemic economic impact may be greater with estimates for the second quarter alone of 2020 showing a $2 \%$ fall in GDP worldwide (15).

Economic damage can directly cause human mortality, particularly in low- or middle-income countries where the healthcare systems may be less robust. The 2014-2016 Ebolavirus epidemic resulted in approximately 11,000 direct deaths (7), but the subsequent overwhelming of the healthcare systems in Guinea, Sierra Leone, and Liberia caused an estimated 10,000 further deaths (16). Avian influenza virus strains can cause fatal disease in humans and introduction into Indonesia in 2009 caused devastation to livelihoods as a result of culling 11 million poultry. The subsequent closure of $30 \%$ of the country's farms created severe disparities in education and nutrition in the worst affected communities (17).

Human activities, such as accelerated deforestation, encroachment into natural animal habitats, or climate change (18), exponentially increase the likelihood of exposure and spillover of novel zoonotic pathogens (19). Due to their potential impact to human health, the WHO and other healthcare agencies have identified pathogens of concern with epidemic or pandemic potential (Table 1). The list represents zoonotic diseases that have caused or may lead to outbreaks, and many lack effective and timely control measures that are crucial for preserving human and animal health.

The One Health approach acknowledges the interdependent relationship between human and animal health, together with our shared environment. The need to increasingly consider all parts of the ecosystem arose as a result of global concerns including antimicrobial resistance and the prevalence of emerging infectious diseases transmitted between animals and humans (36). One Health approaches aim to address such issues using control measures that are ultimately rooted in achieving better veterinary and human health outcomes. Control measures can include detailed epidemiology facilitating identification of transmission routes, disease surveillance, or more overt strategies such as the development of therapeutic and preventative healthcare measures (37). A conceptual framework encompassing a One Health strategy requires concerted interdisciplinary efforts from many professions including social science, healthcare and epidemiology. This level of collaboration is necessary to scale solutions from local to national to global levels to help manage the spread of zoonotic diseases (38).

An identified zoonotic disease of concern, Crimean-Congo Haemorrhagic Fever (CCHF), is a tick-borne disease caused by CCHFV, which affects humans and can cause severe haemorrhagic symptoms with fatal outcomes (39). As noted in Table 1, numerous vertebrates can act as reservoirs of CCHFV to help maintain the virus. Reservoir animals can experience transient viremia and may develop antibody responses towards CCHFV, but no clinical disease is observed (40). As such, further work is needed to identify the main drivers of disease underpinning pathogen transmission.

In this review we discuss the value of integrating veterinary and human research in the field of CCHF by discussing findings from recently developed animal models and underlining the benefit of exploring closely related nairoviruses such as Nairobi Sheep Disease Virus (NSDV) and Hazara Virus (HAZV). In addition, we address current vaccine candidates for preventing $\mathrm{CCHF}$ and a range of approaches that could be key aspects to One Health approaches to combat CCHF.

\section{CRIMEAN-CONGO HAEMORRHAGIC FEVER}

The control and management of zoonotic diseases, such as $\mathrm{CCHF}$, relies heavily on knowledge of the disease. Frequently the causes and impacts of zoonoses are complex and poorly understood (41). Animal reservoirs of CCHFV encompass domestic ungulates, while small mammal and bird populations are thought to play a role in immature tick maintenance and CCHFV transmission $(42,43)$. For a successful One Health approach, it is crucial that sufficient understanding is acquired on animal reservoirs, amplifying hosts and transmission patterns to adequately understand both human and animal disease, while considering CCHFV maintenance and circulation in ticks (44). Attainment of greater knowledge in these areas will support the implementation of control measures, such as prophylactic vaccines for human or animal use (45).

TABLE 1 | WHO Blueprint Diseases and their principal mammalian reservoirs.

\begin{tabular}{|c|c|}
\hline WHO Blueprint Disease (20) & Mammalian reservoir(s) \\
\hline COVID-19 (recently added) & Fruit bats (speculative) (21), pangolin (speculative) (22) \\
\hline Crimean-Congo Haemorrhagic Fever (CCHF) & Cattle (23), goats (24), sheep (23), camels (25), horses (26), donkeys (27) \\
\hline Ebola virus disease & Fruit bats (28) \\
\hline Marburg virus disease & Fruit bats (29) \\
\hline Lassa fever & Multimammate mouse (Mastomys natalensis) (30) \\
\hline MERS coronavirus disease & Bats, alpacas, camels (31) \\
\hline SARS coronavirus disease & Horseshoe bats, palm civets (32) \\
\hline Nipah virus disease & Flying foxes (33), pigs (33) \\
\hline Rift Valley Fever & Sheep, goats, cattle (34) \\
\hline Zika & Rhesus monkeys, sheep, goats, cows, horses, bats, carabaos, orangutans (35) \\
\hline Disease $X$ (future disease outbreak of unknown origin) & Unknown \\
\hline
\end{tabular}


CCHFV is maintained through a tick-vertebrate-tick transmission cycle $(46,47)$. Ticks require a blood feed on small vertebrates to progress in their life cycle from larvae to nymph, and then feeding on large mammals, such as cattle and sheep, to progress from nymph to adult tick (47). Though their role is not fully understood, flighted birds can carry ticks and are thought to contribute to the expansion of tick populations to other territories $(43,48,49)$. CCHFV is contracted through two major routes. The first is through direct contact with infected ticks, either through the bite of an infected tick (44) or tick pulverisation on open wounds exposing an individual to the virus (50). The second transmission route is contact through an open wound with the blood or bodily fluids of an infected person or animal. High risk occupations for CCHFV infection include veterinarians, farmers, and abattoir workers in endemic areas that are in close proximity to livestock (50-52). Human-tohuman transmission can occur following close contact with infected individuals, posing considerable risk for nosocomial outbreaks (53-55).

CCHF is one of the most widespread tick-borne diseases (42). Cases in humans are frequently reported in countries across Asia, Africa and Europe (39) and CCHFV is increasingly being identified in new geographical regions $(56,57)$. Human infections can range in severity from subclinical or mild disease with non-specific symptoms, to severe disease which can cause fatal haemorrhagic disease (54). The mortality rate during annual outbreaks is estimated to be between 5-30\% (39, 46). There are potential differences in CCHF severity between CCHFV endemic geographical regions and it is thought that many human CCHF cases remain subclinical which affect calculated mortality rates (58). A sero-epidemiological survey in Turkey estimated that $88 \%$ of CCHFV infections were subclinical but it is unclear if similar asymptomatic rates occur in other endemic countries (59).

Controlling and curbing CCHFV circulation represents a public health priority, especially in countries where the virus is endemic. Better understanding of disease is needed to accelerate therapeutic and interventional treatments. Animal models are critically important in underpinning our knowledge of disease dynamics and progression. As discussed in the following section, understanding of CCHF can be supported through the study of animal models and closely related nairoviruses.

\section{Animal Models of CCHFV Infection}

CCHFV is typically studied in BSL-4 conditions due to the high risk of severe or fatal haemorrhagic disease in humans, as at present there are no therapeutics or vaccines available (60). Mouse and non-human primate (NHP) models exist for studying CCHFV pathogenesis in these high containment settings. There are a limited number of CCHFV mouse models due to the need to supress or pre-empt the immune system, as infection of immunocompetent mice with CCHFV does not result in overt disease (61). Historically, the first model involved new-born mice, but it was considered inadequate as pathogenesis in new-born mice involved severe damage to the central nervous system (46), a pathology not representative of human disease. Typical murine models involve knock-out of IFN-I receptor $(61,62)$ or STAT1 (63) targeting the type-I interferon (IFN-I) response. The same phenotype can be induced in immunocompetent mice by treatment with antibodies against IFN-1 that block IFN-1 signalling prior to CCHFV infection (64). Such knock-out models have been useful, as some of the main clinical symptoms and disease pathogenesis of CCHF manifest, particularly infection of the liver and spleen, within 4-5 days of inoculation (61-63). These animal models have been informative in determining viral tropism and have been used to assess vaccine candidates $(65,66)$.

Development of NHP models of infection are often considered a pinnacle of replicating human infections in an animal model. However, disease pathology can differ across NHP species for many emerging pathogens, requiring infection studies on a breadth of species to determine a suitable model. For CCHFV, cynomolgus macaques are a suitable model of infection mimicking human disease (67). In cynomolgus macaques, disease pathology appears to be similar to that of humans, with all infected animals developing mild to severe disease, and a proportion of infections displaying a lethal outcome (67). A larger immunocompetent animal model of infection, such as a NHP model, is generally deemed crucial to assess vaccines and therapeutics against CCHFV infection, however, they are more expensive than small animal knock-out models.

\section{CCHFV Analogues for Understanding Orthonairovirus Pathogenicity}

In order to overcome the difficulties of studying pathogens that cause severe disease in humans, researchers frequently use animal-specific pathogens that have a close phylogenetic relationship and pathology profile to those that cause the disease of interest in humans (68).

NSDV, known as Ganjam virus in India, is an Orthonairovirus, closely related to CCHFV (69). NSDV causes Nairobi Sheep Disease (NSD), first described in Kenya during a 1917 outbreak of severe haemorrhagic gastroenteritis in sheep that were relocated from a NSDV-free area to one where NSDV circulated (70). Since then, outbreaks of NSDV have been observed infrequently in sheep and goats.

Like CCHFV, NSDV is also transmitted by ticks. The main symptoms of small ruminant NSDV infection are a febrile illness with diarrhoea, followed by haemorrhages with mortality rates up to $90 \%$ (71-73). However, NSDV has a low level of zoonotic potential with evidence of human infection rarely documented $(74,75)$.

There are a number of analogues between NSDV infection of sheep and CCHFV infection of humans, represented in Table 2. Individuals and animals generally undergo a febrile illness, followed by a haemorrhagic phase in the same organs, predominantly the gastrointestinal tract; both produce leukopenia and injury of the liver and spleen (85). Infection of susceptible hosts with NSDV or CCHFV induces a similar pro-inflammatory immune reaction (71, $86)$ as well as a long-lasting antibody response (52, 87). NSDV infects more organs than CCHFV, and death from NSDV typically occurs within 10 days post infection $(72,73)$, compared to 5-14 days following onset of illness in CCHFV infection (46). 
TABLE 2 | Features of Crimean-Congo Haemorrhagic Fever Virus and Nairobi Sheep Disease virus.

\begin{tabular}{|c|c|c|}
\hline Feature & CCHFV & NSDV \\
\hline Virus structure & Enveloped negative sense ssRNA virus with tripartite genome (76) & $\begin{array}{l}\text { Enveloped negative sense ssRNA virus with tripartite } \\
\text { genome (76) }\end{array}$ \\
\hline $\begin{array}{l}\text { S segment amino acid sequence } \\
\text { similarity }\end{array}$ & \multicolumn{2}{|c|}{$62-63 \%(77)$} \\
\hline Vector & Ixoxid ticks, predominantly Hyalomma genus (78) & $\begin{array}{l}\text { Ixoxid ticks, predominantly Rhipicephalus and Haemophilus } \\
\text { genus (69) }\end{array}$ \\
\hline Clinical Disease & Humans (79) & Sheep and goats (69) \\
\hline Mortality & $5-30 \%(46)$ & $90 \%(80)$ \\
\hline Symptoms in susceptible host & $\begin{array}{l}\text { Fever, myalgia, headache, nausea, soft tissue haemorrhage, epistaxis, } \\
\text { hematemesis (81) }\end{array}$ & $\begin{array}{l}\text { Fever, diarrhoea, gastro-intestinal haemorrhage, soft tissue } \\
\text { haemorrhage (71) }\end{array}$ \\
\hline Tissue pathology & Isolated in lung, liver, and spleen $(82,83)$ & Isolated in lung, liver, spleen, and intestines (84) \\
\hline
\end{tabular}

The major advantage of using NSDV infection in small ruminants as a model for CCHFV infection over the current mouse models is the ability to study lethal Orthonairovirus infection in an immuno-competent organism. The limitation of NSDV is that the virus is of a different species to CCHFV, with a different host tropism. However, the close phylogenetic relationship between NSDV and CCHFV increases the chance that results may be translatable, and the similarities in haemorrhagic pathogenesis suggest that NSDV infection can be used to investigate systemic and immunological effects of Orthonairovirus infection, at a lower risk to human health compared to using NHP models of CCHFV.

HAZV is another nairovirus that may be used as a model of CCHFV infection. Discovered in Pakistan in Ixoxid ticks (88), HAZV can be handled in BSL-2 facilities and is non-pathogenic to humans, unlike CCHFV $(88,89)$. Significantly, HAZV is considered the virus most closely related to CCHFV; HAZV is in the same sero- (90) and genogroup (76) as CCHFV and there is a high level of structural homology between the nucleoprotein of CCHFV and HAZV $(91,92)$.

Researchers have used HAZV infection for pre-clinical investigations, such as in vitro assays to assess the effects of the therapeutic agent ribavirin in combination with other treatments at preventing HAZV infection (93). Ribavirin is commonly prescribed for treating CCHFV (94) and therapeutics which show efficacy against HAZV have been speculated to be effective against CCHFV (93). Parallels between the pathology of CCHFV and HAZV infection have also been observed in immunocompromised mouse models. Infection of IFN-1 knock-out mice with HAZV resulted in lethal disease in all mice (95). The pathology, mortality, and clinical signs were highly similar to those induced by CCHFV infection in the same immunocompromised mouse strains (96). In contrast, wild-type mice were not susceptible to HAZV or CCHFV infection (95).

The close similarity of HAZV with CCHFV has also led to the suggestion to use HAZV to investigate nairoviral infections in the amplifying hosts of CCHFV, namely sheep, goats, and cattle (97). Experimental challenge of domestic animals, including sheep and cattle, with HAZV does not cause symptomatic disease, and HAZV replication was also not observed in sheep or cattle during a recent challenge study (97). Viremia has been observed upon HAZV challenge in a number of other animals including rhesus monkeys and donkeys (98).
As HAZV does not cause overt disease in human or animals, unlike CCHFV and NSDV respectively, HAZV cannot be used to investigate the haemorrhagic pathogenesis observed in human CCHFV infection. A second limitation of HAZV as a model for CCHFV is the lack of natural infection reported in domestic animals and an unknown host species, which limits corollaries being drawn regarding transmission modes or model studies.

Due to the high levels of homology between HAZV and CCHFV, HAZV could provide a viable model virus to study the molecular biology and pathogenicity of CCHFV. HAZV may also be used for the screening of preventative or therapeutic measures that could be translatable for CCHFV, with the use of HAZV precluding the need for experimentation in BSL-4 containment.

\section{CONTROLLING ZOONOTIC TRANSMISSION OF CCHFV}

Despite the presence of CCHFV across a large geographical range and the severity of outbreaks, it is difficult to estimate the disease burden due to the low level of active CCHF surveillance and reliance on passive surveillance with high levels of underreporting. There is also limited diagnostic capability in many endemic regions, with the uncertain frequency of subclinical infections adding to this issue. As a result, it has been suggested that the burden of CCHF disease is greater than estimated from official case reports $(99,100)$. Asymptomatic infections may be common and mild disease can present as non-specific febrile symptoms (101). The awareness of CCHF disease and symptoms is low among physicians and veterinarians even in endemic countries (102), and increasing the awareness of CCHF clinical symptoms among physicians and veterinarians is the first step towards improving access to diagnosis for mild cases, and to prevent nosocomial outbreaks (103).

Implementation of better diagnostic frameworks to improve surveillance strategies for CCHFV infections is an important aspect for a comprehensive One Health approach for disease management (Table 3). A key part of this strategy is the use of rapid laboratory diagnosis for humans by reverse transcription polymerase chain reaction (RT-PCR), a highly sensitive tool to detect CCHFV RNA in individuals (104). Crucially, there are not always laboratory facilities equipped to perform PCR and 
TABLE 3 | The different control measures that may facilitate a CCHF One Health approach and the current status or challenges for their implementation.

Control measure strategy

Immunisation of humans

Immunisation of animals

Tick control

Diagnostic, education, and surveillance

\section{Current status}

Limited licensure of one inactivated vaccine in Eastern Europe

- Multiple vaccine candidates show promise in pre-clinical studies

- No published assessment of candidates in human trials

- Multiple vaccine candidates show promise in pre-clinical studies

- Lack of disease burden means a lack of economic incentive to vaccinate

- Acaricidal agents known to be effective at reducing vector-borne disease rates

- Environmental implications and logistical issues of widespread usage

- PCR available but often limited in capacity or inaccessible

- $\quad$ Sero-surveillance rates increasing (44) diagnose CCHF in less developed rural areas, or they may lack the capacity needed during outbreaks (105). This can result in distant reference laboratories being relied upon, delaying diagnosis (100). The lack of specific clinical presentation also adds difficulty to seeking diagnosis. Improved diagnostic capacity and accessibility in both clinical and field-based settings by the establishment or improvement of regional laboratories in endemic areas would allow earlier detection of positive cases and pre-emptive interventions to be undertaken (106). Increased clinical diagnosis would also identify more asymptomatic and mild cases and improve the estimation of CCHF disease burden.

Active CCHF surveillance is also vital, as has been displayed by the increasing frequency of serological studies to detect antiCCHFV antibodies in human populations $(99,107)$. The data from these sero-surveillance investigations have provided a key insight into the seroprevalence of populations and can be used to evaluate potential risk of exposure in endemic areas (44). Interpretation of such studies should be considered with caution as is that the serological methodologies are often inconsistent and accuracy is not always quantified (58). Additionally, seroprevalence measurement does not resolve the missing CCHF knowledge regarding incidence of subclinical infections versus symptomatic disease. Serological studies in both domestic and wild animal species, as well as surveying distribution and viral presence in tick species, should also be integrated into CCHF surveillance strategies (47, 108). Assessing CCHFV in the amplifying and natural hosts can increase the understanding of the geographical spread of CCHFV and provide estimates of circulating viral quantities, though there is additional complexity to animal and tick surveillance $(99,109)$. Establishment of CCHF surveillance programmes could determine potential levels of risk to human populations in endemic areas by monitoring the prevalence of virus in humans, animals, or tick vectors and this may identify where disease management interventions could be most useful.

CCHF impacts human health, with hundreds of cases officially reported each year and an obvious need for improved control measures including preventative vaccinations or therapeutic treatments (Table 3). There are currently no CCHFV vaccines licenced for widespread usage (110), although one has been licenced in Eastern Europe which uses an inactivated virus platform (111). Studies investigating the immune response to this formalin inactivated vaccine have demonstrated that after four doses, low levels of neutralising antibodies are induced (112). Multiple other vaccine candidates for CCHFV have been developed using a wide range of platforms to deliver vaccine antigens (113-116). For example, two doses of a protein-based subunit CCHFV vaccine that targeted $\mathrm{Gn}$ and $\mathrm{Gc}$ of the glycoprotein precursor achieved neutralising antibody responses, but did not confer protection in mouse challenge models (117). A DNA vaccine expressing the CCHFV full-length glycoprotein induced humoral and cellular immunity and was protective after two doses in mouse challenge models (118). Viral vectored vaccines that used the MVA vector to deliver full length glycoproteins as immunogens against CCHFV also induced humoral and cellular responses; the vaccine was $100 \%$ protective against $\mathrm{CCHFV}$ in immunocompromised mouse models (119). Efforts are now needed to test and then translate putative vaccine candidates into veterinary and human vaccines which can protect against CCHFV (120). It is likely that these medicinal interventions would be stockpiled in endemic countries and used in outbreak situations as has been suggested for other outbreak pathogens such as Nipah or MERS coronavirus (121).

While immunising livestock and poultry against infectious pathogens is an economically important practise to avoid disruption to the food and textiles industry (122), vaccination of farmed animals against diseases can also reduce the likelihood that zoonotic pathogens will be transmitted to humans (123, 124). There are, however, barriers to the development of effective CCHFV vaccines for use in veterinary settings (Table 3 ). There are no economic incentives for farmers, livestock producers or agri-industry to vaccinate against CCHFV. Without an appreciable level of disease in animal hosts, and the accompanying loss of income to those working with animals, the incentive to vaccinate animal reservoirs purely for the benefit of human health may be limited. As such, outside investment may be needed to incentivise this approach. Alternatively combining vaccines that combat impactful veterinary pathogens with a vaccine against CCHFV may persuade key stakeholders to implement vaccination regimens.

Further methods may be considered to manage CCHFV in animal reservoirs. Targeting the disease vector is common in reducing arbovirus transmission (125) and therefore reservoir livestock can be treated with acaricidal agents to remove ticks (Table 3) (126). Unlike with vaccination against CCHFV, treatment of ticks offers direct benefits to animal health (127). 
However, the acaricidal agents can contaminate animal products (128), and annual deaths from organophosphates greatly outnumber those from CCHFV (126). Due to the environmental implications of acaricide usage (129), it would not be feasible to apply acaricides across the large areas needed to supress wild tick populations. Furthermore, the eradication of ticks across large regions of lands would negatively affect the ecosystem, causing unspecified environmental damage (130). While likely to be insufficient alone, careful control of ticks in livestock would be a valuable tool alongside vaccination to reduce $\mathrm{CCHFV}$ infections in humans.

\section{CONCLUSION}

To mitigate the risk and impact posed by CCHF it is vital that sufficient knowledge on human infection and the interplay with the animal reservoir is delineated. Though limited in the past, the increasing availability of animal models has supported the study of CCHF as a disease and the causative agent CCHFV. These models are already playing a significant role assessing the preclinical efficacy of CCHF vaccines. Similarly, the study of closely related nairoviruses such as NSDV and HAZV that are non-pathogenic to humans can further advance our understanding of CCHFV, due to the similarities of the virus infection and subsequent disease. These closely related pathogens can represent valuable models for CCHFV infection, though all research must be viewed with the caveat that there are differences between CCHFV and the model pathogens which must be taken into account.

CCHF has historically been overlooked as a disease of impact due to being largely under reported in humans and the asymptomatic nature of $\mathrm{CCHFV}$ in animal reservoirs that

\section{REFERENCES}

1. Plowright RK, Parrish CR, McCallum H, Hudson PJ, Ko AI, Graham AL, et al. Pathways to zoonotic spillover. Nat Rev Microbiol (2017) 15:502-10. doi: $10.1038 /$ nrmicro.2017.45

2. Monath TP. Vaccines against diseases transmitted from animals to humans: a one health paradigm. Vaccine (2013) 31:5321-38. doi: 10.1016/ j.vaccine.2013.09.029

3. Anderson RM, Fraser C, Ghani AC, Donnelly CA, Riley S, Ferguson NM, et al. Epidemiology, transmission dynamics and control of SARS: the 20022003 epidemic. Philos Trans R Soc Lond B Biol Sci (2004) 359:1091-105. doi: 10.1098/rstb.2004.1490

4. Al-Omari A, Rabaan AA, Salih S, Al-Tawfiq JA, Memish ZA. MERS coronavirus outbreak: Implications for emerging viral infections. Diagn Microbiol Infect Dis (2019) 93:265-85. doi: 10.1016/j.diagmicrobio. 2018.10.011

5. Thanh TT, van Doorn HR, de Jong MD. Human H5N1 influenza: Current insight into pathogenesis. Int J Biochem Cell Biol (2008) 40:2671-4. doi: 10.1016/j.biocel.2008.05.019

6. Formenty P, Libama F, Epelboin A, Allarangar Y, Leroy E, Moudzeo H, et al. Outbreak of Ebola haemorrhagic fever in the Republic of Congo, 2003. Med Trop (2003) 63:291-5 doi: 10.1038/srep14830.

7. Coltart CEM, Lindsey B, Ghinai I, Johnson AM, Heymann DL. The Ebola outbreak, 2013-2016: old lessons for new epidemics. Philos Trans R Soc Lond B Biol Sci (2017) 372:20160297. doi: 10.1098/rstb.2016.0297 enables the virus to circulate undetected. There is little incentive for treatment of animals or surveillance until zoonotic transmission occurs. Without co-ordinated rapid diagnostic testing in tandem with sero-surveillance mechanisms, the first evidence of circulation is frequently after zoonotic transmission, with those working closely with animals put at considerable risk with no foreknowledge (50).

Given the high mortality rates seen during sporadic (but now almost annual) outbreaks of CCHF, better management approaches are essential in countries where CCHFV is endemic and significant health risks exist. This is urgently needed due to the potential for increased incidence of CCHF cases and growing geographical distribution of Hyalomma ticks resulting from environmental changes. There are obvious challenges to alleviating the threat of CCHFV, but ultimately, implementation of a One Health approach to CCHFV management and control while focusing on integrating human and veterinary studies would be of huge benefit to human health.

\section{AUTHOR CONTRIBUTIONS}

CG, JS and EA contributed to writing of the original draft. CG, JS, HS, EA, GL, AL, TL and SB-R contributed to review and editing to produce the final manuscript. All authors contributed to the article and approved the submitted version.

\section{FUNDING}

This research was funded by the Biotechnology and Biological Sciences Research Council (BBSRC) [BB/R019991/1] and the National Institute of Health Research (NIHR) [16/107/06].

8. Neumann G, Noda T, Kawaoka Y. Emergence and pandemic potential of swine-origin H1N1 influenza virus. Nature (2009) 459:931-9. doi: 10.1038/ nature 08157

9. Acter T, Uddin N, Das J, Akhter A, Choudbury TR, Kim S. Evolution of severe acute respiratory syndrome coronavirus 2 (SARS-CoV-2) as coronavirus disease 2019 (COVID-19) pandemic: A global health emergency. Sci Total Environ (2020) 730:138996. doi: 10.1016/ j.scitotenv.2020.138996

10. Worldometers.info. Coronavirus update (LIVE)(2021). Available at: https:// www.worldometers.info/coronavirus/ (Accessed 2nd February 2021).

11. Oh M-D, Park WB, Park S-W, Choe PG, Bang JH, Song K-H, et al. Middle East respiratory syndrome: what we learned from the 2015 outbreak in the Republic of Korea. Korean J Intern Med (2018) 33:233-46. doi: 10.3904/ kjim.2018.031

12. World Bank. GDP (constant 2010 US\$) - Korea, Rep, in: World Bank national accounts data, and OECD National Accounts data files (2010). Available at: https://data.worldbank.org/indicator/NY.GDP.MKTP.KD? locations=KR (Accessed 5th November 2020).

13. Keogh-Brown MR, Smith RD. The economic impact of SARS: how does the reality match the predictions? Health Policy (2008) 88:110-20. doi: 10.1016/ j.healthpol.2008.03.003

14. World Bank. GDP (constant 2010 US\$) - Hong Kong SAR, China, in: World Bank national accounts data, and OECD National Accounts data files (2003). Available at: https://data.worldbank.org/indicator/NY.GDP.MKTP.KD? locations $=\mathrm{HK}$ (Accessed 5th November 2020). 
15. Maliszewska M, Aaditya M, van der Mensbrugghe D. The Potential Impact of COVID-19 on GDP and Trade A Preliminary Assessment. (2020) 9211:6-11. doi: 10.1596/1813-9450-9211

16. Parpia AS, Ndeffo-Mbah ML, Wenzel NS, Galvani AP. Effects of response to 2014-2015 Ebola outbreak on deaths from malaria, HIV/AIDS, and tuberculosis, West Africa. Emerg Infect Dis (2016) 22:433+. doi: 10.3201/eid2203.150977

17. Basuno E, Yusdja Y, Ilham N. Socio-economic impacts of avian influenza outbreaks on small-scale producers in Indonesia. Transbound Emerg Dis (2010) 57:7-10. doi: 10.1111/j.1865-1682.2010.01121.x

18. Elliott RM. Bunyaviruses and climate change. Clin Microbiol Infect (2009) 15:510-7. doi: 10.1111/j.1469-0691.2009.02849.x

19. Kreuder Johnson C, Hitchens PL, Evans TS, Goldstein T, Thomas K, Clements A, et al. Spillover and pandemic properties of zoonotic viruses with high host plasticity. Sci Rep (2015) 5:14830. doi: 10.1038/srep14830

20. WHO. Blueprint Priority Diseases. Available at: https://www.who.int/ blueprint/priority-diseases/en/ (Accessed 19th October 2020).

21. Schlottau K, Rissmann M, Graaf A, Schön J, Sehl J, Wylezich C, et al. SARS-CoV-2 in fruit bats, ferrets, pigs, and chickens: an experimental transmission study. Lancet Microbe (2020) 1:e218-25. doi: 10.1016/S2666-5247(20)30089-6

22. Lam TT-Y, Jia N, Zhang Y-W, Shum MH-H, Jiang J-F, Zhu H-C, et al. Identifying SARS-CoV-2-related coronaviruses in Malayan pangolins. Nature (2020) 583:282-5. doi: 10.1038/s41586-020-2169-0

23. Mustafa ML, Ayazi E, Mohareb E, Yingst S, Zayed A, Rossi CA, et al. Crimean-Congo hemorrhagic fever, Afghanistan, 2009. Emerg Infect Dis (2011) 17:1940-1. doi: 10.3201/eid1710.110061

24. Wangchuk S, Pelden S, Dorji T, Tenzin S, Thapa B, Zangmo S, et al. Crimean-Congo Hemorrhagic Fever Virus IgG in Goats, Bhutan. Emerg Infect Dis (2016) 22:919-20. doi: 10.3201/eid2205.151777

25. Suliman HM, Adam IA, Saeed SI, Abdelaziz SA, Haroun EM, Aradaib IE, et al. Crimean Congo hemorrhagic fever among the one-humped camel (Camelus dromedaries) in Central Sudan. Virol J (2017) 14:147. doi: 10.1186/s12985-017-0816-3

26. Mangombi JB, Roqueplo C, Sambou M, Dahmani M, Mediannikov O, Comtet L, et al. Seroprevalence of Crimean-Congo Hemorrhagic Fever in Domesticated Animals in Northwestern Senegal. Vector-Borne Zoonotic Dis (2020) 20:797-9. doi: 10.1089/vbz.2019.2592

27. Lwande OW, Irura Z, Tigoi C, Chepkorir E, Orindi B, Musila L, et al. Seroprevalence of Crimean Congo hemorrhagic fever virus in Ijara District, Kenya. Vector Borne Zoonotic Dis (2012) 12:727-32. doi: 10.1089/vbz.2011.0914

28. Leroy EM, Kumulungui B, Pourrut X, Pouquet P, Hassanin A, Philippe Y, et al. Fruit bats as reservoirs of Ebola virus. Nature (2005) 438:575-6. doi: $10.1038 / 438575 a$

29. Kuzmin IV, Niezgoda M, Franka R, Agwanda B, Markotter W, Breiman RF, et al. Marburg Virus in Fruit Bat, Kenya. Emerg Infect Dis (2010) 16:352-4. doi: 10.3201/eid1602.091269

30. Lecompte E, Fichet-Calvet E, Daffis S, Koulémou K, Sylla O, Kourouma F, et al. Mastomys natalensis and Lassa fever, West Africa. Emerg Infect Dis (2006) 12:1971-4. doi: 10.3201/eid1212.060812

31. Mohd HA, Al-Tawfiq JA, Memish ZA. Middle East Respiratory Syndrome Coronavirus (MERS-CoV) origin and animal reservoir. Virol J (2016) 13:87. doi: 10.1186/s12985-016-0544-0

32. Shi Z, Hu Z. A review of studies on animal reservoirs of the SARS coronavirus. Virus Res (2008) 133:74-87. doi: 10.1016/j.virusres.2007.03.012

33. Chua KB, Koh CL, Hooi PS, Wee KF, Khong JH, Chua BH, et al. Isolation of Nipah virus from Malaysian Island flying-foxes. Microbes Infect (2002) 4:145-51. doi: 10.1016/S1286-4579(01)01522-2

34. Ngoshe YB, Avenant A, Rostal MK, Karesh WB, Paweska JT, Bagge W, et al. Patterns of Rift Valley fever virus seropositivity in domestic ruminants in central South Africa four years after a large outbreak. Sci Rep (2020) 10:5489. doi: 10.1038/s41598-020-62453-6

35. Vorou R. Zika virus, vectors, reservoirs, amplifying hosts, and their potential to spread worldwide: what we know and what we should investigate urgently. Int J Infect Dis (2016) 48:85-90. doi: 10.1016/j.ijid.2016.05.014

36. Amuasi JH, Lucas T, Horton R, Winkler AS. Reconnecting for our future: The Lancet One Health Commission. Lancet (2020) 395:1469-71. doi: 10.1016/S0140-6736(20)31027-8

37. Nyatanyi T, Wilkes M, McDermott H, Nzeitchueng S, Gafarsi I, Mudakikwa A, et al. Implementing One Health as an integrated approach to health in
Rwanda. BMJ Glob Heal (2017) 2:e000121-e000121. doi: 10.1136/bmjgh2016-000121

38. Rabozzi G, Bonizzi L, Crespi E, Somaruga C, Sokooti M, Tabibi R, et al. Emerging zoonoses: the 'one health approach'. Saf Health Work (2012) 3:7783. doi: 10.5491/SHAW.2012.3.1.77

39. Nasirian H. New aspects about Crimean-Congo hemorrhagic fever (CCHF) cases and associated fatality trends: A global systematic review and metaanalysis. Comp Immunol Microbiol Infect Dis (2020) 69:101429. doi: 10.1016/j.cimid.2020.101429

40. Spengler JR, Estrada-Peña A, Garrison AR, Schmaljohn C, Spiropoulou CF, Bergeron E, et al. A chronological review of experimental infection studies of the role of wild animals and livestock in the maintenance and transmission of Crimean-Congo hemorrhagic fever virus. Antiviral Res (2016) 135:31-47. doi: 10.1016/j.antiviral.2016.09.013

41. Karesh WB, Dobson A, Lloyd-Smith JO, Lubroth J, Dixon MA, Bennett M, et al. Ecology of zoonoses: natural and unnatural histories. Lancet (2012) 380:1936-45. doi: 10.1016/S0140-6736(12)61678-X

42. Spengler JR, Bergeron É., Spiropoulou CF. Crimean-Congo hemorrhagic fever and expansion from endemic regions. Curr Opin Virol (2019) 34:70-8. doi: 10.1016/j.coviro.2018.12.002

43. Palomar AM, Portillo A, Santibáñez P, Mazuelas D, Arizaga J, Crespo A, et al. Crimean-Congo hemorrhagic fever virus in ticks from migratory birds, Morocco. Emerg Infect Dis (2013) 19:260-3. doi: 10.3201/eid1902.121193

44. Sorvillo TE, Rodriguez SE, Hudson P, Carey M, Rodriguez LL, Spiropoulou $\mathrm{CF}$, et al. Towards a Sustainable One Health Approach to Crimean-Congo Hemorrhagic Fever Prevention: Focus Areas and Gaps in Knowledge. Trop Med Infect Dis (2020) 5:113. doi: 10.3390/tropicalmed5030113

45. Kelly TR, Machalaba C, Karesh WB, Crook PZ, Gilardi K, Nziza J, et al. Implementing One Health approaches to confront emerging and reemerging zoonotic disease threats: lessons from PREDICT. One Heal Outlook (2020) 2:1. doi: 10.1186/s42522-019-0007-9

46. Bente DA, Forrester NL, Watts DM, McAuley AJ, Whitehouse CA, Bray M, et al. Crimean-Congo hemorrhagic fever: History, epidemiology, pathogenesis, clinical syndrome and genetic diversity. Antiviral Res (2013) 100:159-89. doi: 10.1016/j.antiviral.2013.07.006

47. Gargili A, Estrada-Peña A, Spengler JR, Lukashev A, Nuttall PA, Bente DA. The role of ticks in the maintenance and transmission of Crimean-Congo hemorrhagic fever virus: A review of published field and laboratory studies. Antiviral Res (2017) 144:93-119. doi: 10.1016/j.antiviral.2017.05.010

48. Jameson LJ, Morgan PJ, Medlock JM, Watola G, Vaux AGC. Importation of Hyalomma marginatum, vector of Crimean-Congo haemorrhagic fever virus, into the United Kingdom by migratory birds. Ticks Tick Borne Dis (2012) 3:95-9. doi: 10.1016/j.ttbdis.2011.12.002

49. Wilhelmsson P, Jaenson TGT, Olsen B, Waldenström J, Lindgren P-E. Migratory birds as disseminators of ticks and the tick-borne pathogens Borrelia bacteria and tick-borne encephalitis (TBE) virus: a seasonal study at Ottenby Bird Observatory in South-eastern Sweden. Parasitol Vectors (2020) 13:607. doi: 10.1186/s13071-020-04493-5

50. Akuffo R, Brandful JAM, Zayed A, Adeji A, Watany N, Fahmy NT, et al. Crimean-Congo hemorrhagic fever virus in livestock ticks and animal handler seroprevalence at an abattoir in Ghana. BMC Infect Dis (2016) 16:324. doi: 10.1186/s12879-016-1660-6

51. Monsalve-Arteaga L, Alonso-Sardón M, Muñoz Bellido JL, Vicente Santiago MB, Vieira Lista MC, López Abán J, et al. Seroprevalence of Crimean-Congo hemorrhagic fever in humans in the World Health Organization European region: A systematic review. PLoS Negl Trop Dis (2020) 14:e0008094. doi: 10.1371/journal.pntd.0008094

52. Mourya DT, Yadav PD, Gurav YK, Pardeshi PG, Shete AM, Jain R, et al. Crimean Congo hemorrhagic fever serosurvey in humans for identifying high-risk populations and high-risk areas in the endemic state of Gujarat, India. BMC Infect Dis (2019) 19:104. doi: 10.1186/s12879-019-3740-x

53. Rehman K, Bettani MAK, Veletzky L, Afridi S, Ramharter M. Outbreak of Crimean-Congo haemorrhagic fever with atypical clinical presentation in the Karak District of Khyber Pakhtunkhwa, Pakistan. Infect Dis Poverty (2018) 7:116. doi: 10.1186/s40249-018-0499-z

54. Ajazaj-Berisha L, Ahmeti S, Dreshaj A, Namani S, Qehaja-Buqaj E, Vishaj A, et al. Nosocomial infection of Crimean-Congo hemorrhagic fever in Kosovo. Eur J Intern Med (2013) 24:e207. doi: 10.1016/j.ejim.2013.08.529 
55. Tsergouli K, Karampatakis T, Haidich A-B, Metallidis S, Papa A. Nosocomial infections caused by Crimean-Congo haemorrhagic fever virus. J Hosp Infect (2020) 105:43-52. doi: 10.1016/j.jhin.2019.12.001

56. Magyar N, Kis Z, Barabás É, Nagy A, Henczkó J, Damjanova I, et al. New geographical area on the map of Crimean-Congo hemorrhagic fever virus: First serological evidence in the Hungarian population. Ticks Tick Borne Dis (2020) 12:101555. doi: 10.1016/j.ttbdis.2020.101555

57. Negredo A, Calle-Prieto F, Palencia-Herrejón E, Mora-Rillo M, Astray-Mochales J, Sánchez-Seco MP, et al. Autochthonous Crimean-Congo Hemorrhagic Fever in Spain. N Engl J Med (2017) 377:154-61 doi: 10.1056/NEJMoa1615162.

58. Raabe VN. Diagnostic Testing for Crimean-Congo Hemorrhagic Fever. J Clin Microbiol (2020) 58:e01580-19. doi: 10.1128/JCM.01580-19

59. Bodur H, Akinci E, Ascioglu S, Öngürü P, Uyar Y. Subclinical infections with Crimean-Congo hemorrhagic fever virus, Turkey. Emerg Infect Dis (2012) 18:640-2. doi: 10.3201/eid1804.111374

60. Weidmann M, Avsic-Zupanc T, Bino S, Bouloy M, Burt F, Chinikar S, et al. Biosafety standards for working with Crimean-Congo hemorrhagic fever virus. J Gen Virol (2016) 97:2799-808 doi: 10.1099/jgv.0.000610.

61. Zivcec M, Safronetz D, Scott D, Robertson S, Ebihara H, Feldmann H. Lethal Crimean-Congo hemorrhagic fever virus infection in interferon $\alpha / \beta$ receptor knockout mice is associated with high viral loads, proinflammatory responses, and coagulopathy. J Infect Dis (2013) 207:1909-21. doi: 10.1093/infdis/jit061

62. Bereczky S, Lindegren G, Karlberg H, Akerström, Klingström J, Mirazimi A. Crimean-Congo hemorrhagic fever virus infection is lethal for adult type I interferon receptor-knockout mice. J Gen Virol (2010) 91:1473-7. doi: 10.1099/vir.0.019034-0

63. Bente DA, Alimonti JB, Shieh W-J, Camus G, Ströher U, Zaki S, et al. Pathogenesis and immune response of Crimean-Congo hemorrhagic fever virus in a STAT-1 knockout mouse model. J Virol (2010) 84:11089-100. doi: 10.1128/JVI.01383-10

64. Lindquist ME, Zeng X, Altmura LA, Daye SP, Delp KL, Blancett C, et al. Exploring Crimean-Congo Hemorrhagic Fever Virus-Induced Hepatic Injury Using Antibody-Mediated Type I Interferon Blockade in Mice. J Virol (2018) 92:e01083-18. doi: 10.1128/JVI.01083-18

65. Zivcec M, Safronetz D, Scott DP, Robertson S, Feldmann H. Nucleocapsid protein-based vaccine provides protection in mice against lethal CrimeanCongo hemorrhagic fever virus challenge. PLoS Negl Trop Dis (2018) 12: e0006628. doi: 10.1371/journal.pntd.0006628

66. Welch SR, Ritter JM, McElroy AK, Harmon JR, Coleman-McCray JD, Scholte FEM, et al. Fluorescent Crimean-Congo hemorrhagic fever virus illuminates tissue tropism patterns and identifies early mononuclear phagocytic cell targets in Ifnar-/- mice. PLoS Pathog (2019) 15:e1008183. doi: 10.1371/journal.ppat.1008183

67. Haddock E, Feldmann F, Hawman DW, Zivcec M, Hanley PW, Saturday G, et al. A cynomolgus macaque model for Crimean-Congo haemorrhagic fever. Nat Microbiol (2018) 3:556-62. doi: 10.1038/s41564-018-0141-7

68. Gowen BB, Holbrook MR. Animal models of highly pathogenic RNA viral infections: Hemorrhagic fever viruses. Antiviral Res (2008) 78:79-90. doi: 10.1016/j.antiviral.2007.10.002

69. Baron MD, Holzer B. Nairobi sheep disease virus/Ganjam virus. Rev Sci Tech (2015) 34:411-7. doi: 10.20506/rst.34.2.2367

70. Montgomery E. On a Tick-Borne Gastro-Enteritis of Sheep and Goats Occurring in British East Africa. J Comp Pathol Ther (1917) 30:28-57. doi: 10.1016/S0368-1742(17)80002-3

71. bin Tarif A, Lasecka L, Holzer B, Baron MD. Ganjam virus/Nairobi sheep disease virus induces a pro-inflammatory response in infected sheep. Vet Res (2012) 43:71. doi: 10.1186/1297-9716-43-71

72. Daubney R, Hudson JR. Nairobi Sheep Disease. Parasitology (1931) 23:50724. doi: $10.1017 /$ S0031182000013895

73. Weinbren MP, Gourlay RN, Lumsden WHR, Weinbren BM. An Epizootic of Nairobi Sheep Disease in Uganda. J Comp Pathol Ther (1958) 68:174-87. doi: 10.1016/S0368-1742(58)80018-1

74. Dandawate CN, Work TH, Webb JKG, Shah KV. Isolation of Ganjam virus from a human case of febrile illness: a report of a laboratory infection and serological survey of human sera from three different states of India. Indian $J$ Med Res (1969) 57:975-82.

75. Mohan Rao CVR, Dandawate CN, Rodrigues JJ, Al E. Laboratory infections with Ganjam virus. Indian J Med Res (1981) 74:319-24.
76. Walker PJ, Widen SG, Wood TG, Guzman H, Tesh RB, Vasilakis N. A Global Genomic Characterization of Nairoviruses Identifies Nine Discrete Genogroups with Distinctive Structural Characteristics and Host-Vector Associations. Am J Trop Med Hyg (2016) 94:1107-22. doi: 10.4269/ajtmh.15-0917

77. Marczinke BI, Nichol ST. Nairobi Sheep Disease Virus, an Important TickBorne Pathogen of Sheep and Goats in Africa, Is Also Present in Asia. Virology (2002) 303:146-51. doi: 10.1006/viro.2002.1514

78. Papa A, Tsergouli K, Tsioka K, Mirazimi A. Crimean-Congo Hemorrhagic Fever: Tick-Host-Virus Interactions. Front Cell Infect Microbiol (2017) 7:213. doi: 10.3389/fcimb.2017.00213

79. Whitehouse CA. Crimean-Congo hemorrhagic fever. Antiviral Res (2004) 64:145-60. doi: 10.1016/j.antiviral.2004.08.001

80. Krasteva S, Jara M, Frias-De-Diego A, Machado G. Nairobi Sheep Disease Virus: A Historical and Epidemiological Perspective. Front Vet Sci (2020) 7:419. doi: $10.3389 /$ fvets.2020.00419

81. Fillâtre P, Revest M, Tattevin P. Crimean-Congo hemorrhagic fever: An update. Med Mal Infect (2019) 49:574-85. doi: 10.1016/j.medmal.2019.09.005

82. Rodrigues R, Paranhos-Baccalà G, Vernet G, Peyrefitte CN. Crimean-Congo hemorrhagic fever virus-infected hepatocytes induce ER-stress and apoptosis crosstalk. PLoS One (2012) 7:e29712-2. doi: 10.1371/journal.pone.0029712

83. Burt FJ, Swanepoel R, Shieh WJ, Smith JF, Leman PA, Greer PW, et al. Immunohistochemical and in situ localization of Crimean-Congo hemorrhagic fever (CCHF) virus in human tissues and implications for CCHF pathogenesis. Arch Pathol Lab Med (1997) 121:839-46.

84. Lasecka L, Bin-Tarif A, Bridgen A, Juleff N, Waters RA, Baron MD. Antibodies to the Core Proteins of Nairobi Sheep Disease Virus/Ganjam Virus Reveal Details of the Distribution of the Proteins in Infected Cells and Tissues. PLoS One (2015) 10:e0124966. doi: 10.1371/journal.pone.0124966

85. Akıncı E, Bodur H, Leblebicioglu H. Pathogenesis of Crimean-Congo Hemorrhagic Fever. Vector-Borne Zoonotic Dis (2013) 13:429-37. doi: 10.1089/vbz.2012.1061

86. Ergönül Ö., Şeref C, Şebnem E, Çelikbaş A, Baykam N, Dokuzoğuz. Cytokine response in crimean-congo hemorrhagic fever virus infection. J Med Virol (2017) 89:1707-13. doi: 10.1002/jmv.24864

87. Davies FG, Casals J, Jesset DM, Ochieng P. The serological relationships of Nairobi sheep disease virus. J Comp Pathol (1978) 88:519-23. doi: 10.1016/ 0021-9975(78)90005-1

88. Begum F, Wisseman CLJr, Casals J. Tick-Borne Viruses Of West Pakistan: II. Hazara Virus, A New Agent Isolated From Ixodes Redikorzeviticks From The Kaghan Valley, W. Pakistan12. Am J Epidemiol (1970) 92:192-4. doi: 10.1093/oxfordjournals.aje.a121197

89. Fuller J, Sutees RA, Slack GS, Mankouri J, Hewson R, Barr JN. Rescue of Infectious Recombinant Hazara Nairovirus from cDNA Reveals the Nucleocapsid Protein DQVD Caspase Cleavage Motif Performs an Essential Role other than Cleavage. J Virol (2019) 93:e00616-19. doi: 10.1128/JVI.00616-19

90. Casals J, Tignor GH. The Nairovirus Genus: Serological Relationships. Intervirology (1980) 14:144-7. doi: 10.1159/000149175

91. Matsumoto Y, Nouchi T, Ohta K, Nishio M. Regulation of Hazara virus growth through apoptosis inhibition by viral nucleoprotein. Arch Virol (2019) 164:1597-607. doi: 10.1007/s00705-019-04236-7

92. Surtees R, Ariza A, Punch EK, Trinh CH, Dowall SD, Hewson R, et al. The crystal structure of the Hazara virus nucleocapsid protein. BMC Struct Biol (2015) 15:24. doi: 10.1186/s12900-015-0051-3

93. Flusin O, Vigne S, Peyrefitte CN, Bouloy M, Crance J-M, Iseni F. Inhibition of Hazara nairovirus replication by small interfering RNAs and their combination with ribavirin. Virol J (2011) 8:249. doi: 10.1186/1743-422X-8-249

94. Yilmaz G, Sunbal M, Yapar D, Baykam N, Hasanoglu I, Guner R, et al. Ribavirin in Treatment of Crimean-Congo Hemorrhagic Fever (CCHF): An International Multicenter Retrospective Analysis. Open Forum Infect Dis (2016) 3:668. doi: 10.1093/ofid/ofw172.531

95. Dowall SD, Findlay-Wilson S, Rayner E, Pearson G, Pickersgill J, Rule A, et al. Hazara virus infection is lethal for adult type I interferon receptorknockout mice and may act as a surrogate for infection with the humanpathogenic Crimean-Congo hemorrhagic fever virus. J Gen Virol (2012) 93:560-4. doi: 10.1099/vir.0.038455-0

96. Garrison AR, Smith DR, Golden JW. Animal Models for Crimean-Congo Hemorrhagic Fever Human Disease. Viruses (2019) 11:590. doi: 10.3390/ v11070590 
97. Hartlaub J, von Armin F, Fast C, Somova M, Mirazimi A, Groschup MH, et al. Sheep and Cattle Are Not Susceptible to Experimental Inoculation with Hazara Orthonairovirus, a Tick-Borne Arbovirus Closely Related to CCHFV. Microorganisms (2020) 8:1927. doi: 10.3390/microorganisms 8121927

98. Smirnova SE. A comparative study of the Crimean hemorrhagic feverCongo group of viruses. Arch Virol (1979) 62:137-43. doi: 10.1007/ BF01318066

99. Nasirian H. Crimean-Congo hemorrhagic fever (CCHF) seroprevalence: A systematic review and meta-analysis. Acta Trop (2019) 196:102-20. doi: 10.1016/j.actatropica.2019.05.019

100. Al-Abri SS, Al Abaidani I, Fazlalipour M, Mostafavi E, Leblebicioglu H, Pschenichnaya N, et al. Current status of Crimean-Congo haemorrhagic fever in the World Health Organization Eastern Mediterranean Region: issues, challenges, and future directions. Int J Infect Dis (2017) 58:82-9. doi: 10.1016/j.ijid.2017.02.018

101. Tanyel E, Sunbul M, Fletcher TE, Leblebicioglu H. Aetiology of PCR negative suspected Crimean-Congo hemorrhagic fever cases in an endemic area. Pathog Glob Health (2016) 110:173-7. doi: 10.1080/20477724.2016.1213958

102. Ahmed A, Tanveer M, Saqlain M, Khan GM. Knowledge, perception and attitude about Crimean Congo Hemorrhagic Fever (CCHF) among medical and pharmacy students of Pakistan. BMC Public Health (2018) 18:1333. doi: 10.1186/s12889-018-6248-1

103. Papa A. Diagnostic approaches for Crimean-Congo hemorrhagic fever virus. Expert Rev Mol Diagn (2019) 19:531-6. doi: 10.1080/14737159.2019.1615450

104. Mazzola LT, Kelly-Cirino C. Diagnostic tests for Crimean-Congo haemorrhagic fever: a widespread tickborne disease. BMJ Glob Heal (2019) 4:e001114-e001114. doi: 10.1136/bmjgh-2018-001114

105. Bartolini B, Gruber CE, Koopmans M, Avşič T, Bino S, Christova I, et al. Laboratory management of Crimean-Congo haemorrhagic fever virus infections: perspectives from two European networks. Euro Surveill (2019) 24:1800093. doi: 10.2807/1560-7917.ES.2019.24.5.1800093

106. Blair PW, Kuhn JH, Pecor DB, Apanaskevich DA, Kortepeter MG, Cardile AP, et al. An Emerging Biothreat: Crimean-Congo Hemorrhagic Fever Virus in Southern and Western Asia. Am J Trop Med Hyg (2019) 100:16-23. doi: 10.4269/ajtmh.18-0553

107. Vawda S, Goedhals D, Bester PA, Burt F. Seroepidemiologic Survey of Crimean-Congo Hemorrhagic Fever Virus in Selected Risk Groups, South Africa. Emerg Infect Dis (2018) 24:1360-3. doi: 10.3201/eid2407.172096

108. De Liberato C, Frontoso R, Magliano A, Montemaggiori A, Autorino GL, Sala M, et al. Monitoring for the possible introduction of Crimean-Congo haemorrhagic fever virus in Italy based on tick sampling on migratory birds and serological survey of sheep flocks. Prev Vet Med (2018) 149:47-52. doi: 10.1016/j.prevetmed.2017.10.014

109. Spengler JR, Bergeron É., Rollin PE. Seroepidemiological Studies of CrimeanCongo Hemorrhagic Fever Virus in Domestic and Wild Animals. PLoS Negl Trop Dis (2016) 10:e0004210. doi: 10.1371/journal.pntd.0004210

110. Dowall SD, Carroll MW, Hewson R. Development of vaccines against Crimean-Congo haemorrhagic fever virus. Vaccine (2017) 35:6015-23. doi: 10.1016/j.vaccine.2017.05.031

111. Papa A, Papadimitriou E, Christova I. The Bulgarian vaccine CrimeanCongo haemorrhagic fever virus strain. Scand J Infect Dis (2011) 43:225-9. doi: 10.3109/00365548.2010.540036

112. Mousavi-Jazi M, Karlberg H, Papa A, Christova I, Mirazimi A. Healthy individuals' immune response to the Bulgarian Crimean-Congo hemorrhagic fever virus vaccine. Vaccine (2012) 30:6225-9. doi: 10.1016/j.vaccine.2012.08.003

113. Aligholipour Farzani T, Földes K, Ergünay K, Gurdal H, Bastug A, Ozkul A. Immunological Analysis of a CCHFV mRNA Vaccine Candidate in Mouse Models. Vaccines (2019) 7:115. doi: 10.3390/vaccines7030115

114. Rahpeyma M, Samarbaf-Zadeh A, Makvandi M, Ghadiri AA, Dowall SD, Fotouhi F. Expression and characterization of codon-optimized CrimeanCongo hemorrhagic fever virus Gn glycoprotein in insect cells. Arch Virol (2017) 162:1951-62. doi: 10.1007/s00705-017-3315-3

115. Hinkula J, Devignot S, Åkerström S, Karlberg H, Wattrang E, Bereczky S, et al. Immunization with DNA Plasmids Coding for Crimean-Congo Hemorrhagic Fever Virus Capsid and Envelope Proteins and/or Virus-Like Particles Induces Protection and Survival in Challenged Mice. J Virol (2017) 91:e02076-16 doi: 10.1128/JVI.02076-16
116. Dowall SD, Buttigieg KR, Findlay-Wilson SJD, Rayner E, Pearson G, Miloszewska A, et al. A Crimean-Congo hemorrhagic fever (CCHF) viral vaccine expressing nucleoprotein is immunogenic but fails to confer protection against lethal disease. Hum Vaccin Immunother (2016) 12:51927 doi: 10.1080/21645515.2015.1078045.

117. Kortekaas J, Vloet RPM, McAuley AJ, Shen X, Bosch BJ, de Vries L, et al. Crimean-Congo Hemorrhagic Fever Virus Subunit Vaccines Induce High Levels of Neutralizing Antibodies But No Protection in STAT1 Knockout Mice. Vector Borne Zoonotic Dis (2015) 15:759-64 doi: 10.1089/ vbz.2015.1855.

118. Garrison AR, Shoemaker CJ, Golden JW, Fitzpatrick CJ, Suchak JJ, Richards MJ, et al. A DNA vaccine for Crimean-Congo hemorrhagic fever protects against disease and death in two lethal mouse models. PLoS Negl Trop Dis (2017) 11:e0005908 doi: 10.1371/journal.pntd.0005908.

119. Buttigieg KR, Dowall SD, Findlay-Wilson S, Miloszewska A, Rayner E, Hewson R, et al. A Novel Vaccine against Crimean-Congo Haemorrhagic Fever Protects $100 \%$ of Animals against Lethal Challenge in a Mouse Model. PLoS One (2014) 9:e91516 doi: 10.1371/journal.pone.0091516.

120. Hawman DW, Ahlén G, Appelberg KS, Meade-White K, Hanley PW, Scott D, et al. A DNA-based vaccine protects against Crimean-Congo haemorrhagic fever virus disease in a Cynomolgus macaque model. Nat Microbiol (2021) 6:187-95. doi: 10.1038/s41564-020-00815-6

121. Gouglas D, Christodoulou M, Plotkin SA, Hatchett R. CEPI: Driving Progress Toward Epidemic Preparedness and Response. Epidemiol Rev (2019) 41:28-33. doi: 10.1093/epirev/mxz012

122. Roth JA, Tuggle CK. Livestock Models in Translational Medicine. ILAR J (2015) 56:1-6. doi: 10.1093/ilar/ilv011

123. Strausbaugh LJ, Berkelman RL. Human Illness Associated with Use of Veterinary Vaccines. Clin Infect Dis (2003) 37:407-14. doi: 10.1086/375595

124. Wang G-L, Gray GC, Chen J-M, Ma M-J. Will China's H7N9 Control Strategy Continue to Be Effective? Open Forum Infect Dis (2019) 6:1-14. doi: 10.1093/ofid/ofz258

125. Huang Y-JS, Higgs S, Vanlandingham DL. Arbovirus-Mosquito Vector-Host Interactions and the Impact on Transmission and Disease Pathogenesis of Arboviruses. Front Microbiol (2019) 10:22. doi: 10.3389/fmicb.2019.00022

126. Laing G, Aragrande M, Canali M, Savic S, De Meneghi D. Control of Cattle Ticks and Tick-Borne Diseases by Acaricide in Southern Province of Zambia: A Retrospective Evaluation of Animal Health Measures According to Current One Health Concepts. Front Public Heal (2018) 6:45. doi: 10.3389/fpubh.2018.00045

127. Norval RAI, Sutherst RW, Kurki J, Kerr JD, Gibson JD. The effects of the brown ear-tick, Rhipicephalus appendiculatus, on milk production of Sanga cattle. Med Vet Entomol (1997) 11:148-54. doi: 10.1111/j.13652915.1997.tb00305.x

128. Camoni I, Ghirotti M, De Meneghi M, Diverio S, Generali T, Izzo P, et al. Chlorfenvinphos residues in milk from traditionally managed cows in Southern Province, Zambia. Vet Res Commun (1990) 14:503-6. doi: 10.1007/BF00367062

129. De Meneghi D, Stachurski F, Adakal H. Experiences in Tick Control by Acaricide in the Traditional Cattle Sector in Zambia and Burkina Faso: Possible Environmental and Public Health Implications. Front Public Heal (2016) 4:239. doi: 10.3389/fpubh.2016.00239

130. Rajput ZI, Hu S, Chen W, Arijo AG, Xiao C. Importance of ticks and their chemical and immunological control in livestock. J Zhejiang Univ Sci B (2006) 7:912-21. doi: 10.1631/jzus.2006.B0912

Conflict of Interest: The authors declare that the research was conducted in the absence of any commercial or financial relationships that could be construed as a potential conflict of interest.

Copyright (C) 2021 Gilbride, Saunders, Sharpe, Maze, Limon, Ludi, Lambe and BelijRammerstorfer. This is an open-access article distributed under the terms of the Creative Commons Attribution License (CC BY). The use, distribution or reproduction in other forums is permitted, provided the original author(s) and the copyright owner(s) are credited and that the original publication in this journal is cited, in accordance with accepted academic practice. No use, distribution or reproduction is permitted which does not comply with these terms. 